University of Nebraska - Lincoln

DigitalCommons@University of Nebraska - Lincoln

3-18-2008

\title{
Multi-angle remote sensing of forest light use efficiency by observing PRI variation with canopy shadow fraction
}

\author{
Forrest G. Hall \\ University of Maryland - Eastern Shore, fghall@ltpmail.gsfc.nasa.gov \\ Thomas Hilker \\ University of British Colo \\ Nicholas C. Coops \\ University of British Colo \\ Alexei Lyapustin \\ Goddard Earth Science \& Technology Center \\ Karl F. Huemmrich \\ University of Maryland - Baltimore County \\ See next page for additional authors \\ Follow this and additional works at: https://digitalcommons.unl.edu/nasapub \\ Part of the Physical Sciences and Mathematics Commons
}

Hall, Forrest G.; Hilker, Thomas; Coops, Nicholas C.; Lyapustin, Alexei; Huemmrich, Karl F.; Middleton, Elizabeth M.; Margolis, Hank; Drolet, Guillaume; and Black, T. Andrew, "Multi-angle remote sensing of forest light use efficiency by observing PRI variation with canopy shadow fraction" (2008). NASA Publications. 15.

https://digitalcommons.unl.edu/nasapub/15

This Article is brought to you for free and open access by the National Aeronautics and Space Administration at DigitalCommons@University of Nebraska - Lincoln. It has been accepted for inclusion in NASA Publications by an authorized administrator of DigitalCommons@University of Nebraska - Lincoln. 


\section{Authors}

Forrest G. Hall, Thomas Hilker, Nicholas C. Coops, Alexei Lyapustin, Karl F. Huemmrich, Elizabeth M. Middleton, Hank Margolis, Guillaume Drolet, and T. Andrew Black 


\title{
Multi-angle remote sensing of forest light use efficiency by observing PRI variation with canopy shadow fraction
}

\author{
Forrest G. Hall ${ }^{\mathrm{a}, *}$, Thomas Hilker ${ }^{\mathrm{b}}$, Nicholas C. Coops ${ }^{\mathrm{b}}$, Alexei Lyapustin ${ }^{\mathrm{c}}$, Karl F. Huemmrich ${ }^{\mathrm{a}}$, \\ Elizabeth Middleton ${ }^{\mathrm{d}}$, Hank Margolis ${ }^{\mathrm{e}}$, Guillaume Drolet ${ }^{\mathrm{e}}$, T. Andrew Black ${ }^{\mathrm{f}}$ \\ a Joint Center for Earth Systems Technology, University of Maryland, Baltimore County-Goddard Space Flight Center, Greenbelt Maryland, 20771, Code 614.4, USA \\ b Faculty of Forest Resource Management, University of British Columbia, 2424 Main Mall, Vancouver, BC, Canada V6T 1Z4 \\ ' Goddard Earth Science E' Technology Center, GSFC, Greenbelt Md. 20771, Code 614.4 \\ ' NASA Goddard Space Flight Center, Greenbelt Md. 20771, Code 614.4, USA \\ e Faculté de Foresterie et de Géomatique, Université Laval, Québec, QC, Canada G1K 7P4 \\ ${ }^{\mathrm{f}}$ Faculty of Land and Food Systems, University of British Columbia, 2357 Main Mall, Vancouver, BC, Canada V6T 124
}

\section{A R T I C L E I N F O}

\section{Article history:}

Received 31 August 2007

Received in revised form 16 March 2008

Accepted 18 March 2008

\section{Keywords:}

Remote sensing

Photochemical reflectance index

Light use efficiency

Forest

PRI

LUE

Multi-angle

Shadow fraction

\begin{abstract}
A B S T R A C T
We show that observed co-variations at sub-hourly time scales between the photochemical reflectance index (PRI) and canopy light use efficiency (LUE) over a Douglas-fir forest result directly from sub-hourly leaf reflectance changes in a $531 \mathrm{~nm}$ spectral window roughly $50 \mathrm{~nm}$ wide. We conclude then, that over a forest stand we are observing the direct effects of photosynthetic down-regulation on leaf-level reflectance at $531 \mathrm{~nm}$. Key to our conclusion is our ability to simultaneously measure the LUE and reflectance of the Douglas-fir stand as a function of shadow fraction from the "hot spot" to the "dark spot" and a new finding herein, based on radiative transfer theory, that the magnitude of a normalized reflectance difference index (NDRI) such as PRI can vary with shadow fraction only in case the reflectance of the shaded and sunlit leaves differ in at least one of the NDRI bands.

Our spectrometer measurements over a nearly 6 month period show that at a forest stand scale, only two NDRIs (both containing a band near $570 \mathrm{~nm}$ ) vary with shadow fraction and are correlated with LUE; an NDRI with a band centered at $531 \mathrm{~nm}$ roughly $50 \mathrm{~nm}$ wide, and another near $705 \mathrm{~nm}$. Therefore, we are able to conclude that only these two bands' reflectance differ between the sunlit and the shaded elements of the canopy. Their reflectance changes on time scales of a few minutes or less. Our observations also show that the reflectance changes at $531 \mathrm{~nm}$ are more highly correlated with variations in canopy light use efficiency when only sunlit canopy elements are viewed (the hot spot), than when only shaded elements (the dark spot) are viewed. Taken together then, these results demonstrate that the observed sub-hourly changes in foliage reflectance at $531 \mathrm{~nm}$ and $705 \mathrm{~nm}$ can only result from corresponding variations in photosynthetic rates. The importance of our results are as follows: (1) We show that variations in PRI with LUE are a direct result of rapid changes in foliage reflectance at $531 \mathrm{~nm}$ resulting from photosynthetic down-regulation, and can be observed at forest scales. (2) Our findings also suggest a new sensor and methodology for the direct retrieval from space of changes in forest LUE by measuring PRI as a function of shadow fraction using a multi-angle spectrometer simultaneously retrieving both shadow fraction and PRI.
\end{abstract}

(c) 2008 Elsevier Inc. All rights reserved.

\section{Introduction}

Where vegetation on land is the dominant surface cover, the land flux of moisture to the atmosphere depends almost entirely on moisture transport from the soil by the plants through their stomata, which in turn is almost completely controlled by vegetative physiological responses to: (1) incident photosynthetically active radiation (PAR) between 400 and $700 \mathrm{~nm}$, (2) atmospheric properties

\footnotetext{
* Corresponding author.

E-mail address: fghall@ltpmail.gsfc.nasa.gov (F.G. Hall).
}

$\left(\mathrm{CO}_{2}\right.$ concentration, and temperature and humidity) in the canopy air space and, (3) root zone conditions, soil properties, soil moisture and nutrient environment (Sellers, 1985, 1987).

Water and carbon flux to and from the atmosphere are in turn intimately coupled through the plant's stomatal conductance and its carbon assimilation rate (Ball et al., 1986). Assimilation rate is in turn proportional to the incident PAR (the radiation between 400 and $700 \mathrm{~nm}$ ), the fraction of absorbed PAR (Fapar) by the photosynthetic elements of the plant canopy (i.e. "green" Fapar) and the efficiency $\varepsilon$ with which this absorbed PAR can be used to produce biomass, also known as LUE (Monteith, 1972, 1977)-here, we will use LUE and $\varepsilon$ interchangeably. While 20 years of remote sensing research has honed 
the ability to accurately measure green Fapar using satellite measures of Normalized Difference Vegetation Index (NDVI) and PAR using satellite upwelling PAR observations, determination of $\varepsilon$ at landscape and global scales remains challenging (Hall et al., 2006; Running et al., 2004; Turner et al., 2005).

LUE is a critical component when calculating landscape level carbon, water and energy exchange. Surface-atmosphere transfer models such as the Simple Biosphere Model (SiB2) (Sellers et al., 1992) and the Biosphere-Atmosphere Transfer Model (BATS2) (Dickenson et al., 1998) compute carbon assimilation rate from satellite measures of PAR and Fapar, and implicitly calculate LUE using functions limited by various environmental factors known to inhibit plant LUE. Both SiB2 and BATS have been evaluated against tower measurements acquired in prairie grasslands during FIFE (Sellers et al., 1992a). While these models perform well when accurate values of input parameters and meteorological forcings are available at plot levels, Collelo et al. (1998) found that their accuracy was degraded at the landscape level by the lack of knowledge of some of their input parameters, primarily soil moisture and nutrient levels in the root zone.

If vegetation LUE values across a landscape can be measured directly by satellite, these values can be combined with satellite measures of PAR and Fapar to compute vegetation carbon assimilation rates. While possible only under cloud-free conditions, these satellite landscape measures could be "compared" (using a data assimilation scheme) with similar estimates from models like SiB2 or BATS during clear satellite overpasses, to "tune" model internal parameter values or external forcing data. Such data assimilation algorithms obtain "best estimates" of the model parameter values or external forcing data by iterating them to minimize spatial differences between model predictions and satellite measured values of carbon assimilation rates across the landscape. Because carbon assimilation and evapotranspiration rates are closely linked in SiB2 and BATS they will then provide improved estimates of these rates between clear satellite overpasses.

Variations in vegetation LUE occur in a variety of ways for a variety of reasons. Of interest to this study are "excess light" situations, that are situations where leaves are not able to fully utilize PAR absorption for photosynthesis. In such instances, plant biological mechanisms down-regulate photosynthesis to preserve internal moisture and prevent damage to photosynthetic structures. A number of studies have described this mechanism (Adams \& Demmig-Adams, 1994; Demmig-Adams \& Adams, 1992; Demmig-Adams et al., 1996; Niyogi, 1999; Osmond et al., 1999; Pfundel \& Bilger, 1994) where downregulation is triggered by a lowering of $\mathrm{pH}$ in the plant thylakoid membrane. Lower $\mathrm{pH}$ activates two types of changes affecting the leaf reflectance at $531 \mathrm{~nm}$, first described by Gamon et al. $(1992,1997)$ and elaborated by Peñuelas et al. (1994, 1995); Filela et al., 1996; Gamon and Surfus, 1999): (1) membrane conformational changes linked to the $\mathrm{pH}$ gradient and (2) pigment conversion from violaxanthin, a xanthophyll cycle pigment bound to the PSII light harvesting complex (LHCII), to zeaxanthin, via intermediate antheraxanthin. This bio- chemical conversion process is reversed when resources are again adequate to support light levels available for photosynthesis. An important consequence of this down-regulation is a measurable difference in the light absorption coefficient between violaxanthin, zeaxanthin and antheraxanthin. As violaxanthin is de-epoxidized, the higher absorption coefficients of zeaxanthin and antheraxanthin cause leaf reflectance to decrease between about 500 and $550 \mathrm{~nm}$ centered at $\sim 531 \mathrm{~nm}$, as shown in Fig. 1. However, the reflectance change is only 0.004 at an absolute reflectance of 0.06 , a relative change of about 7\%; difficult to recover in the presence of other factors that can cause variations in spectral reflectance of similar or larger magnitudes.

In order to detect these relatively small changes in leaf spectral reflectance in the presence of other confounding factors, Gamon et al. (1992, 1993, 1997) formulated and applied the photochemical reflectance index (PRI), a normalized difference reflectance index (NDRI) composed of a detection band straddling the $531 \mathrm{~nm}$ spectral region and a reference band relatively insensitive to the xanthophyll signal at $570 \mathrm{~nm}$.

$$
\mathrm{PRI}=\frac{\rho_{531}-\rho_{570}}{\rho_{531}+\rho_{570}}
$$

Gamon's pioneering study demonstrated the principal connection between photoprotective leaf chemistry alterations and reflectance at the both the leaf and plant level for a range of values of the epoxidation state (ES) of the xanthophyll cycle pigments.

The relationship between $\varepsilon$ and PRI is clearly observable at the leaf level over a wide range of species (Filela et al., 1996; Gamon \& Surfus, 1999; Peñuelas et al., 1993, 1994, 1995, 1997); however, as a result of the relatively small changes in reflectance at $531 \mathrm{~nm}$, generalization of this relationship to forest stand scales remains difficult (Barton \& North, 2001, Rahman et al., 2001, 2004). PRI is also affected by viewangle, soil background reflectance, leaf angle distribution (at larger view angles) and leaf area (Asner, 1998; Barton \& North, 2001; Chen \& Leblanc, 1997; Strahler \& Jupp, 1990).

Nevertheless, a number of studies have demonstrated correlations between PRI and LUE at kilometer scales by comparing aircraft and satellite data to tower eddy flux measurements (Drolet et al., 2005; Drolet et al., in press; Fuentes et al., 2006; Nichol et al., 2000; Rahman et al., 2001, 2004). The first satellite demonstrations of LUE-PRI correlations were reported by (1) Rahman et al. (2004), who explored the MODIS PRI signal and its relation to forest LUE, (2) Asner et al. (2004) who reported Hyperion PRI observations of an Amazonian forest and (3) Drolet et al. (2005) over the BOREAS Old Aspen flux tower in the Canadian boreal forest. But these studies did not demonstrate that the correlations result from reflectance changes at the leaf level brought on by changes in leaf xanthophyll cycle pigments. In fact, a number of other studies have demonstrated that variations in PRI at the scale of forest stands can be caused by other factors, for example, variations in foliage
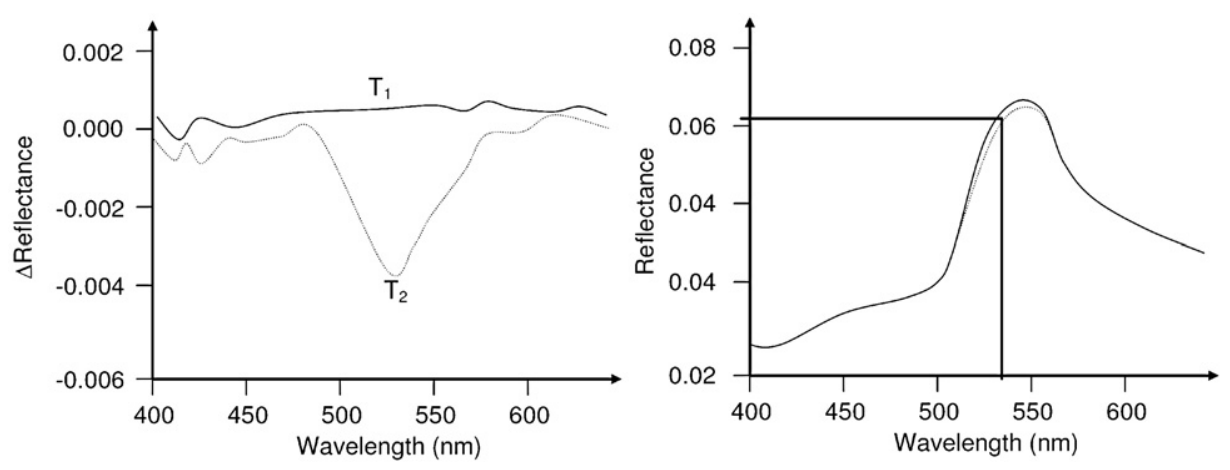

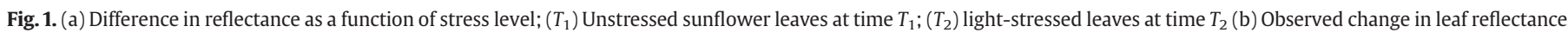
From Gamon et al., 1990 . 
chlorophyll-carotenoid pool sizes, viewing and illumination geometry, canopy structure and background reflectance (Barton \& North, 2001; Gamon et al., 2001; Guo \& Trotter 2004; Nichol et al., 2002; Rahman et al., 2001; Sims \& Gamon, 2002).

Thus, an important question remains; with all these variations, can the relatively small changes in reflectance at $531 \mathrm{~nm}$ resulting from sub-hourly changes in light saturation be observed over forest stands? In this study we investigate this question over a Douglas-fir forest using analytic methods and tower-based, full-spectrum observations.

\section{Methods}

\subsection{Inference framework}

As seen in Hilker et al. (2008), tower-based spectrometer measurements show that throughout the 2006 growing season, PRI observed by our spectrometer is correlated to the LUE calculated from the eddy-covariance measurements. But is this correlation arising from factors other than the light-excess photosynthetic down-regulation and its associated reductions in reflectance at $531 \mathrm{~nm}$ ? To address this question, we develop and execute an inference framework.

The framework is of necessity, somewhat complex, involving three null hypotheses, the sequential rejection or non-rejection of which, on the basis of our observations, lead to our conclusions. Before we state the hypotheses formally, a brief overview of the logic flow may be helpful (see Fig. 2). The first hypothesis NH1 is based on a test of whether or not simultaneous spectrometer measures of PRI and shadow fraction viewed by the spectrometer co-vary. If they do not, the reflectance at $531 \mathrm{~nm}$ cannot differ from sunlit to shadowed leaves, as we show using radiative transfer theory (see Section 2.1.1). There, we show that the magnitude of any NDRI can co-vary with shadow fraction only if the reflectance in at least one band differs from sunlit to shadowed leaves. Hence, if our observed spectrometer PRI and shadow fraction values do not co-vary, the reflectance in neither the reference nor the detection band can differ between shadowed and sunlit leaves. When this is the case, photosynthetic down-regulation via the xanthophyll cycle should not be active since, as we discussed previously, excess light in the sunlit leaves triggers down-regulation and a reflectance reduction at $531 \mathrm{~nm}$. As shown in the NH1 box of Fig. 2, failure to reject NH1 implies that our observed PRI and shadow fraction values do not co-vary, and we can conclude without further analysis that the observed PRI-LUE relationship is not related to changes in the xanthophyll pigments. If we are able to reject NH1, PRI is varying with shadow fraction, and we move to second null hypothesis, $\mathrm{NH} 2$ (see Section 2.1.2) to determine if the covariation is a result of the $531 \mathrm{~nm}$ band. To test NH2 we form an NDRI using the $570 \mathrm{~nm}$ reference band and a band removed from the 531

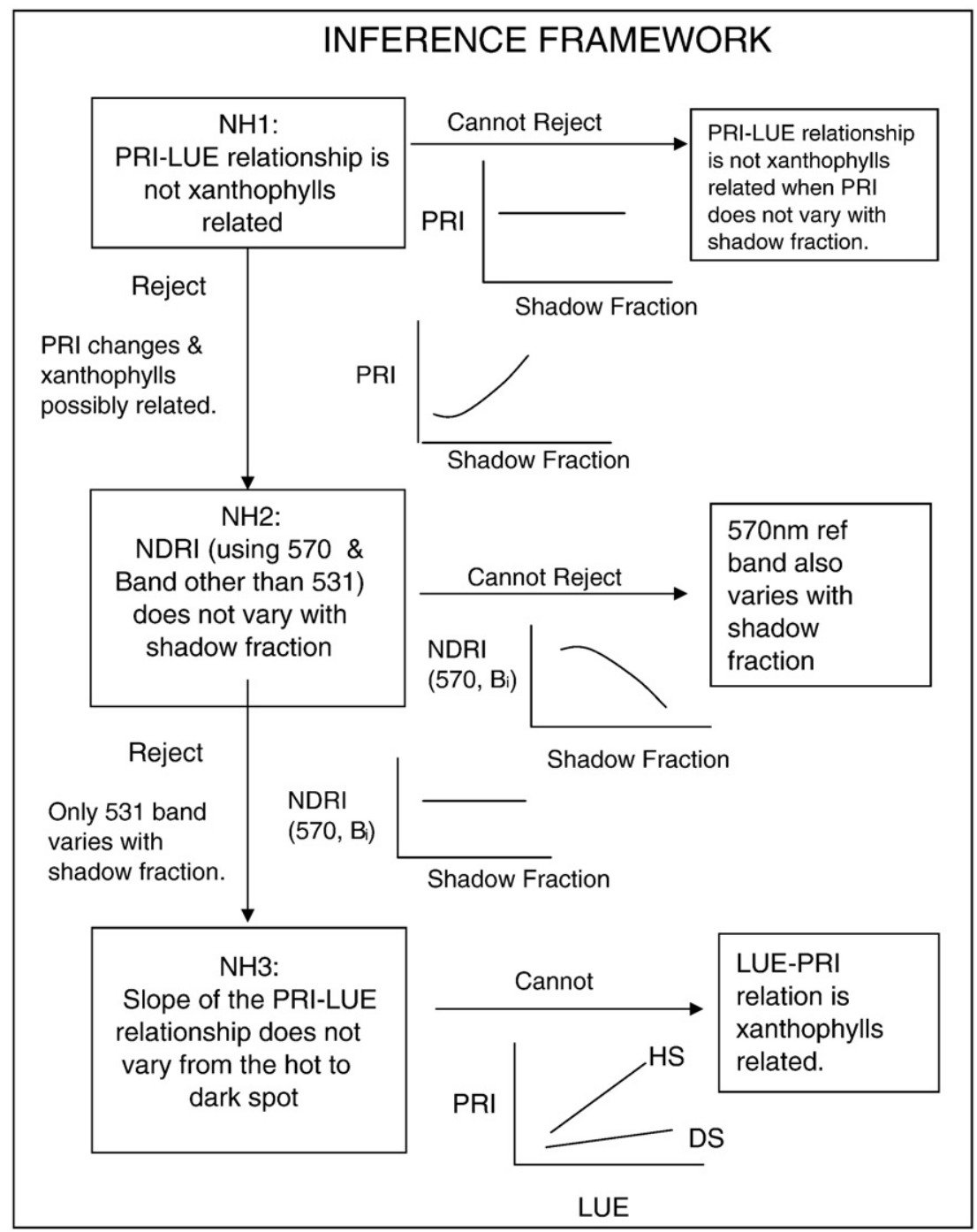

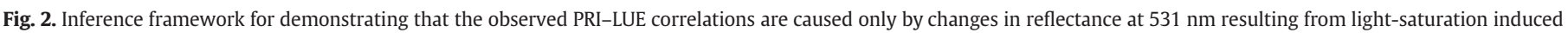
changes in leaf xanthophylls. 
region; we chose a chlorophyll absorption band. If this NDRI does not vary with shadow fraction, then we can safely conclude that neither band varies with shadow fraction. That is, we can show by rejecting $\mathrm{NH} 2$ that the observed co-variation with shadow fraction is a result of differences in the sunlit and shadowed reflectance in the $531 \mathrm{~nm}$ band. Although only one NDRI would do, we will choose two chlorophyll absorption bands and show that we are able to reject $\mathrm{NH} 2$; this not only shows that the 570 reflectance and shadow fraction do not co-vary but also proves that the reflectance in these two important chlorophyll bands also do not differ from sunlit to shadowed leaves; Therefore variations in foliage chlorophyll cannot explain our observed seasonal variation in PRI with LUE.

With NH3 (Section 2.1.3), we test to see if the slope of the PRI-LUE relation increases significantly from the dark spot to the hot spot. If so, this result is consistent with photosynthetic down-regulation being stronger in sunlit leaves than shaded ones, hence that forest LUE is directly related to the changes in the xanthophyll cycle pigments.

Once we have completed analysis of our spectrometer observations using the inference framework in Fig. 2, one final element remains to address broader questions; are the bands used for PRI robust over time? Are other biological phenomena evident with other NDRIs? This last element of the framework is described in Section 2.2.

In the next few sections, we formally state the three null hypotheses, develop the rational for them, then evaluate them sequentially using the data acquired at the Douglas-fir forest site.

2.1.1. NH1: The observed correlations between LUE and PRI are not related to reflectance changes induced by xanthophyll cycle pigments

Rejection of NH1 is necessary (but not sufficient) to establish leaflevel changes in xanthophyll cycle pigments as the proximate cause of canopy-level changes in PRI. Sufficient conditions are to be provided in null hypotheses 2 and 3 below.

$\mathrm{NH} 1$ rests on two facts;

(i) That the sunlit leaves in a canopy are much more likely to be photosynthetically down-regulated, hence should display a xanthophyll-induced reflectance differential to less lightsaturated, shaded leaves and,

(ii) A new result we develop and report here, that an NDRI cannot vary with canopy shadow fraction, unless one of the band's reflectance varies from sunlit to shaded leaves, which we prove in the next section.

Given (i) and (ii) above, when any NDRI, including PRI, is observed not to vary with shadow fraction (or sunlit fraction) then the reflectance in each band must be the same for both the sunlit and shaded canopy elements, hence the xanthophyll cycle cannot be active. On the contrary, if a variation in NDRI with shadow fraction is observed, it follows that in one or both bands the sunlit to shaded leaf reflectance differs. Rejection of $\mathrm{NH} 1$ provides conclusive evidence that leaf reflectance in one or both bands of the NDRI differ from sunlit to shaded leaves.

2.1.1.1. NH1: A proof. To prove that rejecting NH1 establishes a relationship between PRI and changes in the xanthophyll cycle pigments, we derive an analytic expression for the measured PRI as a function of shadow fraction. For a given fraction of shadow viewed by the radiometer (a function of the relative azimuth between the radiometer and the sun and the solar azimuth) the measured reflectance for Lambertian scatterers, is given by a sum of contributions from shadowed and sun-lit canopy elements:

$\rho_{\text {ifov }}(\lambda)=\frac{\left[\alpha_{\mathrm{sh}} \rho_{\mathrm{sh}}(\lambda) F_{\text {diff }}(\lambda)+\alpha_{\mathrm{sun}} \rho_{\mathrm{sun}}(\lambda) F_{\mathrm{t}}(\lambda)\right]}{F_{\mathrm{t}}(\lambda)}$

Here, $\alpha_{\mathrm{sh}},\left(\alpha_{\mathrm{sun}}=1-\alpha_{\mathrm{sh}}\right)$ is a fraction of shadowed and sun-lit canopy, $\rho_{\text {sh }}(\lambda), \rho_{\text {sun }}(\lambda)$ are respectively, shadowed and sunlit canopy reflectance, and $F_{\text {diff }}$ and $F_{\mathrm{t}}$ is respectively, diffuse and total (diffuse plus direct) surface irradiance. Note that the shadowed canopy is illuminated by the diffuse light only, and sun-lit canopy is illuminated by both direct and diffuse sunlight. The linear mixture model shown in Eq. (2) is valid under the assumption that scattering among canopy elements is negligible. Given the high absorptivity and low transmissivity in the visible bands, this is a reasonable approximation.

Denoting the fraction of diffuse to total irradiance $\delta_{\text {dif }}=F_{\text {diff }}(\lambda) / F_{\mathrm{t}}$ ( $\lambda$, we can rewrite Eq. (2) as

$\rho_{\text {ifov }}(\lambda)=\alpha_{\text {sh }} \delta_{\text {dif }}(\lambda) \rho_{\text {sh }}(\lambda)+\alpha_{\text {sun }} \rho_{\text {sun }}(\lambda)$

As the spectrometer measures spectra at a $62^{\circ}$ zenith angle, it encounters a wide range of shadow fraction with changing relative azimuth $\varphi$ and sees the hot spot at a solar elevation of $28^{\circ}$ and $\varphi=180^{\circ}$. It is difficult to assess precisely the amount of shadow fraction viewed by the spectrometer; the shadow fraction calculations from the LiDAR model described in the next section considers only mutual crown shading, disregarding internal needle and shoot-level shading. This effectively increases the size of the sunlit elements and interstitial gaps in the forest stand, resulting in broadening of the hot spot (e.g. Gerstl \& Borel, 1992). Nevertheless, we used this simplified assessment of LiDAR-based shadow fraction to ascertain if the variation in the observed NDRI with shadow fraction is consistent with $\mathrm{NH} 1$, which can be re-stated as $\rho_{\mathrm{sh}}(\lambda)=\rho_{\text {sun }}(\lambda)$. If it is not consistent, then there must be an additional variation in NDRI with illumination condition (shadow fraction) due to leaf chemistry differences causing $\rho_{\text {sh }}(\lambda) \neq \rho_{\text {sun }}(\lambda)$.

Under NH1, when measured PRI variations are not caused by light saturation-induced xanthophyll cycle changes, $\rho_{\text {sh }}(\lambda)=\rho_{\text {sun }}(\lambda)=\rho(\lambda)$, and Eq. (3) may be rewritten as

$\rho_{\text {ifov }}(\lambda)=\rho(\lambda)\left[1-\alpha_{\text {sh }}\left(1-\delta_{\text {dif }}(\lambda)\right)\right]$.

In the Results section we use Eq. (4) to compute the dependence on each band in the NDRI with shadow fraction, and then compute the resulting simulated NDRI. The calculation shows that NDRI does not vary with shadow fraction unless the reflectance in at least one band differs between the sunlit and shaded canopy elements. Before we do that, we describe directly below our method of obtaining simultaneously the PRI and shadow fraction data necessary to test the hypotheses.

2.1.1.2. Spectrometer and LUE observations for testing NH1. To obtain the data necessary to test $\mathrm{NH} 1$, an experimental setting is required in which spectral observations include a range of sunlit and shadowed canopy. We utilized data obtained from the AMSPEC, a spectrometer experimental set up (Fig. 3) established at a Fluxnet Canada site (Hilker et al., 2007), which acquires temporal full-spectrum reflectance in both shadowed and sunlit canopies. The site is located between Courtenay and Campbell River on Vancouver Island, British Columbia, Canada $\left(49^{\circ} 52 \mathrm{~N}, 125^{\circ} 20 \mathrm{~W}\right)$ at $300 \mathrm{~m}$ above sea level. The coniferous forest consists of $80 \%$ Douglas-fir, $17 \%$ western red cedar (Thuja plicata Donn ex D. Don) and 3\% western hemlock (Tsuga heterophylla (Raf.) Sarg.) (Humphreys et al., 2006; Morgenstern et al., 2004) and is a second-growth stand planted in 1949, following harvest of the original stand (Goodwin, 1937). Year round eddy covariance flux measurements have been acquired since 1997. The site has been part of the Fluxnet-Canada research network since 2002.

A wide range of shadowed and sunlit canopy was scanned from an automated multi-angular spectrometer platform installed at a height of $45 \mathrm{~m}$ ( $\approx 10 \mathrm{~m}$ above the tree canopy) at an open lattice type flux-tower (Hilker et al., 2007). Continuous reflectance measurements from this platform were obtained from April 1st 2006, to October 15th, 2006. The instrument features a motor driven probe that allows observations in a $330^{\circ}$ view area around the tower (Fig. 3). The probe rotates in $11.5^{\circ}$ intervals every $30 \mathrm{~s}$, thereby completing a full rotation every $15 \mathrm{~min}$. No observations are made between an azimuth of $220^{\circ}$ and $250^{\circ}$ (defined from geodetic north) due to obstruction by the tower. 
(a)

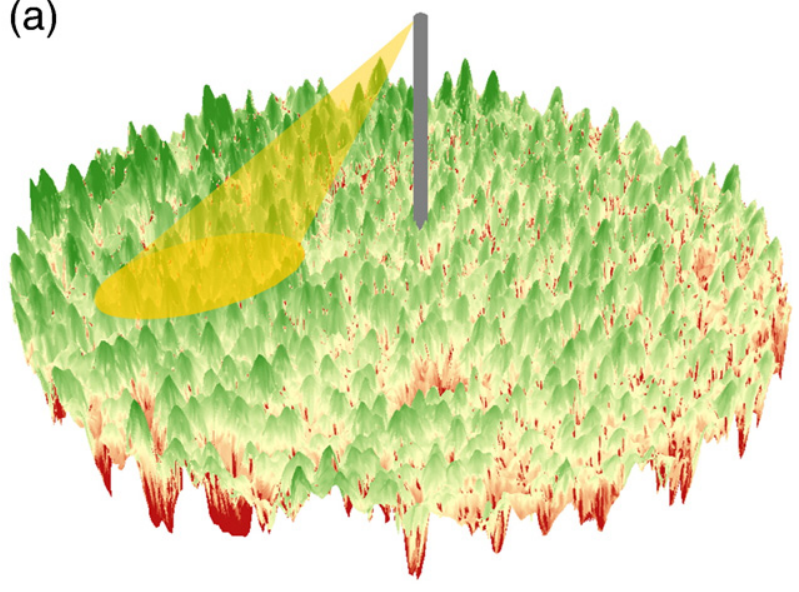

(b)

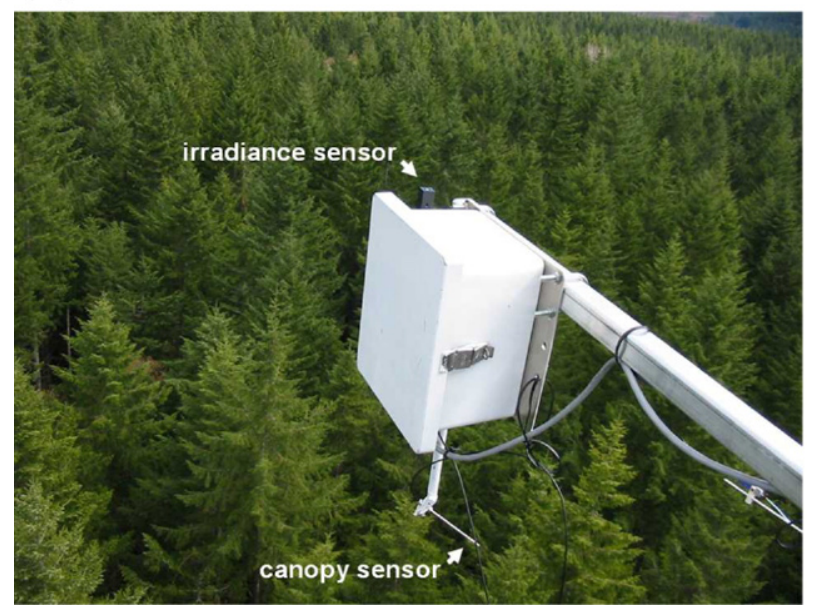

Fig. 3. (a) LiDAR derived canopy structure model of Douglas-fir forest at a radius of $1 \mathrm{~km}$ around the tower. The height of the tower (center) is overdrawn in this diagram for illustration purposes. (b) A dual channel radiometer is mounted on the DF49 fluxnettower with a vertical zenith angle (VZA) of $62^{\circ}$. A motor moves the canopy sensor $360^{\circ}$ every $15 \mathrm{~min}$. Data are recorded every $5 \mathrm{~s}$, year round.

The spectro-radiometer used is a Unispec-DC (PP Systems, Amesbury, MA, USA) featuring 256 contiguous bands with a nominal bandwidth of $3 \mathrm{~nm}$ and a nominal range of operation between 350 and $1200 \mathrm{~nm}$. To allow sampling under varying sky conditions, canopy reflectance is obtained from simultaneous measurements of solar irradiance and radiance (Fig. 3), sampled every $5 \mathrm{~s}$ from sunrise to sunset. The upward pointing probe is equipped with a cosine receptor (PP-Systems, Fig. 3a) to correct sky irradiance measurements for varying solar elevations. The downward looking probe is measuring canopy reflectance at a zenith angle of $62^{\circ}$ (Chen \& Black, 1991). The probe's instantaneous field of view (IFOV) is $20^{\circ}$. The outer diameter of the instrument's footprint is approximately $62 \mathrm{~m}$ at canopy height, while the elliptic instantaneous view area of the probe has a major axis of about $17.9 \mathrm{~m}$ and a minor axis of around $3.5 \mathrm{~m}$ (Fig. 3a). A complete description of the instrument and its setup can be found in Hilker et al. (2007).

LUE was inferred from eddy covariance based measures of net ecosystem production (NEP), daytime estimates of respiration, calculated using the annual exponential relationship between nighttime net ecosystem exchange (NEE) and soil temperature at 5-cm depth after applying a logarithmic transformation to correct for heteroscedasticity (Black et al., 1996, Goulden \& Crill, 1997), and up and downward looking quantum sensors (Model 190 SZ, LI-COR,
Lincoln, Nebraska, USA), installed above and below the canopy. A detailed description on the derivation of $\varepsilon$ from eddy flux data at the site can be obtained from Schwalm et al. (2006) and Hilker et al. (2007).

2.1.1.3. Computing shadow fractions viewed by the spectrometer. Testing NH1 requires estimation of shadow fraction for each spectral measurement to establish if estimates of canopy shadow fractions change the PRI response. Hilker et al. (2008, in press) introduced a technique to derive canopy shadow fractions from airborne laser scanning (LiDAR). Non-ground LiDAR returns were used to generate a three-dimensional canopy structure model (CSM) describing the structure of the forest canopy for the circular footprint of the radiometer (Fig. 3a). The generated CSM was then used to simulate the shadow fractions for a given half-hour interval using a hillshade algorithm (ArcGIS, Esri Inc. Redlands, California, USA). This algorithm models clear-sky canopy shadowing (but includes no needle or shoot shadowing) for a given forest surface and view and sun position and is commonly applied in three-dimensional mapping (Pellegrini et al., 2003, Van Den Eeckhaut et al., 2005). A full description of the algorithm used to obtain canopy shadow fractions can be found in Hilker et al., in press). The output is a 256-grayscale raster of the same size and resolution as the input CSM, where each pixel represents the illumination conditions at its specific location. Totally shaded areas, for instance, are assigned a pixel value of 0 while illuminated areas contain pixel values between 1 and 255 depending on the amount of direct solar radiation they receive. A threshold can be used to classify pixels into either shaded or sun-lit.

2.1.2. NH2: When the reference band for an NDRI whose value varies with shadow fraction is combined with any other band, this new NDRI does not vary with shadow fraction

This hypothesis test is designed to show that for any NDRI for which we fail to reject NH1, only one band of the NDRI (the detection band) differs in reflectance between the sunlit and shaded leaves. Here we must show that a different NDRI formed from the reference band does not vary with shadow fraction.

If we cannot reject $\mathrm{NH} 2$, we can infer that the detection band and not the reference band differs in reflectance between the sunlit and shaded leaves.

2.1.3. NH3: The slope of the NDRI-LUE relationship does not vary with the fraction of sunlit canopy viewed by the spectrometer

The NH3 test is designed to show that the reflectance difference between sunlit and shaded leaves in the detection band is induced by photo down-regulation in the sunlit leaves related to LUE variations, as opposed to some other cause of reflectance change at $531 \mathrm{~nm}$. To execute this step, we examine the correlation between PRI for a range of tower-observed values of LUE at both the hot spot and at the dark spot. If a significant and positive correlation can be demonstrated between PRI and LUE and the slope of this relationship is greater when fully sunlit canopy is viewed than fully shaded canopy (changes in forest-stand reflectance at $531 \mathrm{~nm}$ will be larger with changes in LUE as more sunlit, light saturated leaves are viewed by the spectrometer) then necessary and sufficient evidence has been established to prove that changes in the PRI signal are a result of changes in the xanthophyll cycle pigments. If we cannot reject NH3, then NDRI is not responding to LUE changes, but to some other biological phenomena that induces differences in the reflectance of sunlit and shaded leaves in those particular bands.

\subsection{Are the bands used for PRI robust over time? Are other biological} phenomena evident with other NDRIs?

The final element of our inference framework is to see whether or not there are other NDRI changes with shadow fraction other than the 
PRI bands, and if not, whether the PRI bands are located in precisely the right place, with the right width and stable over our observing period. Our spectrometer configuration at the Douglas-fir site (Fig. 3) provides an opportunity to generalize the examination of all NDRIs, using a generalization of the inference framework described above, that are formed from each pair-combination of spectrometer bands between 400 and $900 \mathrm{~nm}$, under the full range of illumination and viewing conditions encountered during our observing period April 1st 2006 to October 15th, 2006. Because the hillshades algorithm does not take into account the effects of diffuse sky radiation on shadow fraction, we could not extend the approach described above for testing $\mathrm{NH} 1$ and $\mathrm{NH} 2$ to cloudy periods.

Instead, we employed a parametric approach to characterize the dependence of the observed NDRIs on view and illumination geometry. Under similar illumination conditions, variations in view and illumination geometry are directly related to the variation in viewed shadow fraction. We chose the parametric characterization of Roujean et al. (1992), and the methods of Los et al. (2005) and Hilker et al. (2008) to parameterize the directional dependence of NDRI on view and illumination geometry, hence viewed shadow fraction. For kernels, we chose the commonly applied functions, Li-Sparse, RossThick (LSRT) kernels (Lucht et al., 2000; Strugnell \& Lucht, 2001; Wanner et al., 1995). This method of characterization is meaningful only for (1) observations acquired under similar sky illumination conditions (because the BRF is more distinct under clear skies than under overcast conditions) and (2) restricted ranges of LUE (the LSRT kernels do not account for sunlit to shaded leaf reflectance differences induced by canopy physiology). Thus we grouped our observations into different strata using the ratio of tower-measured direct to diffuse radiation (Q) for stratification of sky conditions and the tower-based calculated LUE. Q-LUE pairs were matched with the exact time of the spectrometer measurements.

For strata we used 16 LUE levels, LUE $=0$ to LUE $>3.0$ in steps of 0.2 and 10 cloudiness levels $Q$ from $Q=0$ to $Q>8.5$ in steps of 0.5 (Hilker et al., 2008). $Q$ was determined using a direct and diffuse PAR sensor, a BF3, Delta-T Devices Ltd., Burwell, UK. LUE was inferred as described earlier in Section 2.1.1.2.

Directional reflectance effects from shadow fraction were smallest under overcast situations, increasing with increasingly clear skies.

Los et al. (2005) used the semi-empirical kernel notation to express the NDRI BRF.

$\operatorname{NDRI}\left(\theta_{\mathrm{v}}, \theta_{\mathrm{s}}, \Delta \phi\right)=k_{\mathrm{i}}+k_{\mathrm{g}} K_{\mathrm{L}}\left(\theta_{\mathrm{v}}, \theta_{\mathrm{s}}, \Delta \phi, \frac{h}{b}, \frac{b}{r}\right)+k_{\mathrm{v}} K_{\mathrm{R}}\left(\theta_{\mathrm{v}}, \theta_{\mathrm{s}}, \Delta \phi\right)$

where

$k_{\mathrm{i}}{ }^{\prime} \quad$ isotropic scattering coefficient

$\mathrm{k}_{\mathrm{g}}{ }^{\prime} \quad$ geometric scattering coefficient

$K_{\mathrm{L}} \quad$ Li-Sparse Kernel

$k_{\mathrm{v}}{ }^{\prime} \quad$ volumetric scattering coefficient

$K_{\mathrm{R}} \quad$ Ross-Thick Kernel

$\theta_{\mathrm{v}} \quad$ view zenith angle

$\theta_{\mathrm{s}} \quad$ solar zenith angle

$\Delta \phi \quad$ relative azimuth angle

$\frac{h}{b} \quad$ crown relative height $=1$ (Justice et al., 1998; Wanner et al., 1995)

$\frac{b}{r} \quad$ crown relative shape $=2$ (Justice et al., 1998; Wanner et al., 1995)

Variations in $k_{\mathrm{i}} k_{\mathrm{g}} k_{\mathrm{v}}$ should reflect the "shape" of the NDRI BRF functions if their NDRI changes with spectrometer-viewed shadow fraction as tower-measured LUE values change. The kernel values will be affected primarily by shadow fraction viewed by the spectrometer since crown relative height and relative shape of the mature Douglasfir change much more slowly (months) than tower-measured LUE values (minutes); hence, changes in the kernel values will be driven primarily by the difference in canopy optical properties between shaded and sunlit leaves. As we have shown previously, canopy optical properties that vary equally between sunlit and shaded leaves will have no effect on the variation in NDRIs with shadow fraction.

Eq. (5) was fit to the observations contained in each Q-LUE stratum using a robust linear least squares algorithm (bi-square-weighted iterations). Changes in canopy reflectance due to different physiological states are then manifest in the variation of the empirical kernel weights of each Q-LUE class with LUE. Thus, if for an NDRI composed of the $531 \mathrm{~nm}$ band, the kernel weights show high variation and correlation with LUE, and other NDRIs formed from other bands show little correlation, our analysis demonstrates a powerful and general empirical proof of the relationship between tower-level LUE and leaflevel reflectance changes at $531 \mathrm{~nm}$.

\section{Results}

\subsection{Testing $\mathrm{NH} 1$}

To establish the necessary (but not sufficient) conditions that leaflevel changes in xanthophyll cycle pigments are the proximate cause of canopy-level changes in PRI, we compared the theoretical simulation of NDRI as a function of shadow fraction, Eq. (4) with NDRIs computed from our spectrometer measurements. Under $\mathrm{NH} 1$, $\rho_{\text {sh }}(\lambda)=\rho_{\text {sun }}(\lambda)$. For $\rho(\lambda)$ in Eq. (4) we used hot spot values measured by the spectrometer (Table 1 ) for a given sweep (09/28/2006, 12:45 Pacific Standard Time) as well as the shadow fractions modeled by LiDAR. The results of this analysis are plotted in Fig. 4a.

The modeled PRI values (green symbols) in Fig. 4a demonstrate that an NDRI does not change with shadow fraction if the reflectance in both bands does not differ between sunlit and shaded canopy elements. However, PRI calculated from our spectrometer measurements are plotted in Fig. 4b. Measured PRI values clearly co-vary with shadow fraction. A $t$-test shows that $\mathrm{NH} 1$ can be rejected with a confidence $>95 \%$. The question remains though as to whether the measured change in PRI in Fig. $4 \mathrm{~b}$ is a result of a reflectance change at $531 \mathrm{~nm}$ or a change in the reference band, $570 \mathrm{~nm}$. To resolve this question, test $\mathrm{NH} 2$, the second component of the inferential framework.

\subsection{Testing $\mathrm{NH} 2$}

NH2 was tested using two NDRIs composed of two radiometer simulated MODIS bands, 10 (defined as arithmetic mean of band 483 and $493 \mathrm{~nm}$ ) and 13 (defined as arithmetic mean of band 663 and $673 \mathrm{~nm}$ ) and the $570 \mathrm{~nm}$ band as reference band (although the failure to reject NH2 for an NDRI formed from either band 10 or 13 and the 570 band would have sufficed). As can be seen in Fig. $5 a$ and $b$ these NDRIs are largely independent of shadow fraction (green plotting symbols) hence the $\mathrm{NH} 2$ can be rejected (again, with a confidence $>95 \%$ ) and we can conclude that the reflectance of the reference band at $570 \mathrm{~nm}$ and bands 13 or 10 are not different from sunlit to shaded leaves in the Douglas-fir forest (the abrupt change in the reference band at $50^{\circ}$ relative azimuth is not completely understood but does not affect the overall significance of the non-zero slope of PRI with shadow fraction).

Table 1

Hotspot values measured by the spectro-radiometer (at direct backscatter solar geometry) for a spectrometer sweep (09/28/2006, 12:45 Pacific Standard Time

\begin{tabular}{lllll}
\hline Band & MODIS 11 & $570 \mathrm{~nm}$ & MODIS 10 & MODIS 13 \\
\hline Spec Hotspot $\rho$ & 0.072 & 0.084 & 0.036 & 0.041 \\
\hline
\end{tabular}


(a)

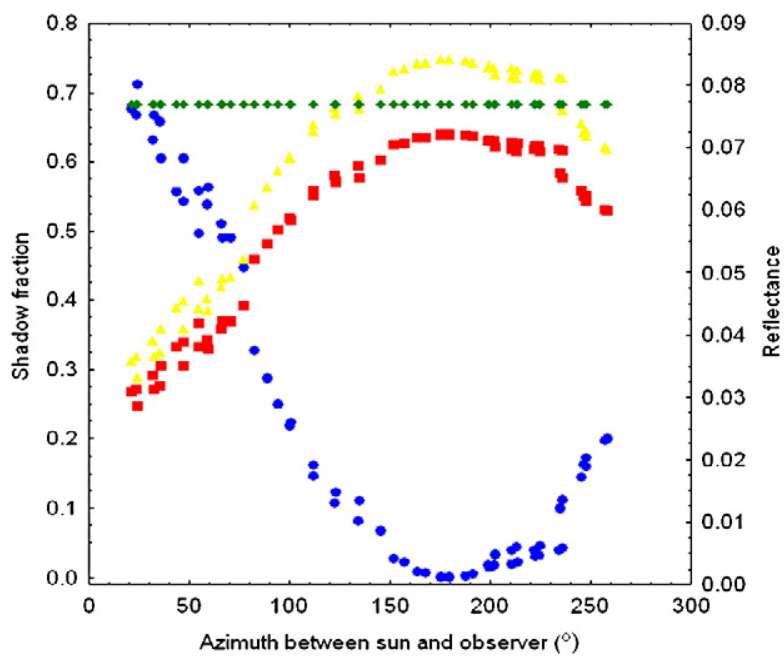

- Shadow fraction - 2531 (modelled) $\quad \rho 570$ (modelled) * PRI(modelled) (b)

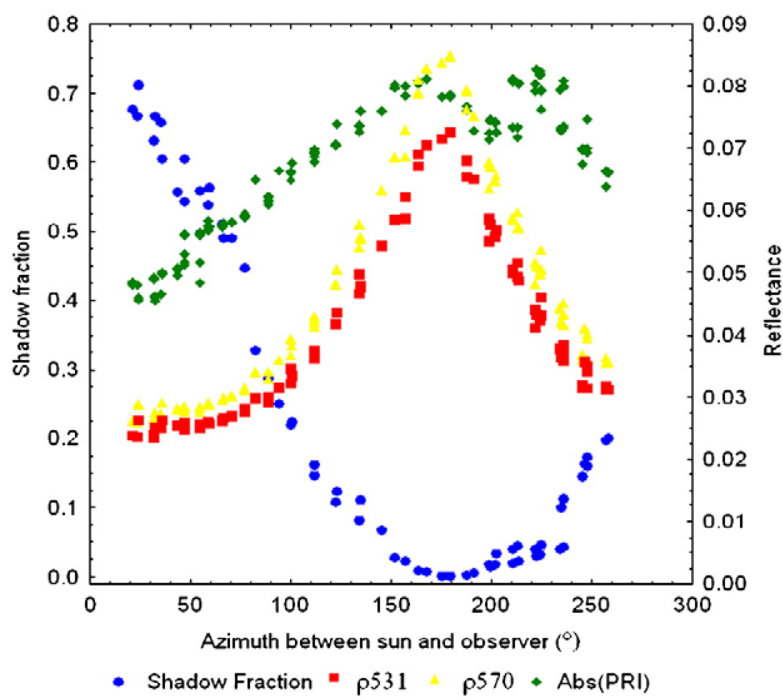

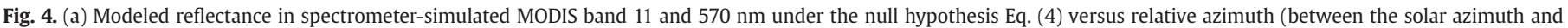
spectrometer heading). (b) Actual spectrometer measurements.

Taking this together with the rejection of the NH1 in Fig. 4 we can conclude that the reflectance band at $531 \mathrm{~nm}$ does differ significantly from shaded to sunlit canopy elements. We also learn from Fig. 5a and b that MODIS bands 10 and 13, both chlorophyll absorption bands, do not vary in reflectance from the sunlit to shaded leaves, hence their variations cannot be involved in explaining observed rapid variations in LUE at the Doug Fir tower site.

\subsection{Testing $N H 3$}

$\mathrm{NH} 3$ of the inference framework is designed to determine whether or not the reflectance change we see in the $531 \mathrm{~nm}$ band is related to xanthophyll-cycle induced differences between the sunlit and shaded canopy elements and LUE.

To test NH3 we analyzed nine clear-sky spectrometer azimuthal scans acquired on 9 different days between April 30 and August 21st 2006. During this period, LUE values ranged from 0.1 to $0.5 \mathrm{~g} \mathrm{C} \mathrm{MJ}^{-1}$. We examined the correlation between spectrometer-measured PRI and tower-inferred LUE using spectrometer reflectance acquired at the hotspot and at the dark spot on each spectrometer scan. As discussed earlier, the expectation was that the PRI when viewing mostly lightsaturated leaves at the hot spot would demonstrate a higher sensitivity to LUE differences than when viewing mostly shadowed leaves at the dark spot. As shown in Fig. 6a the slope of the LUE-PRI (a)

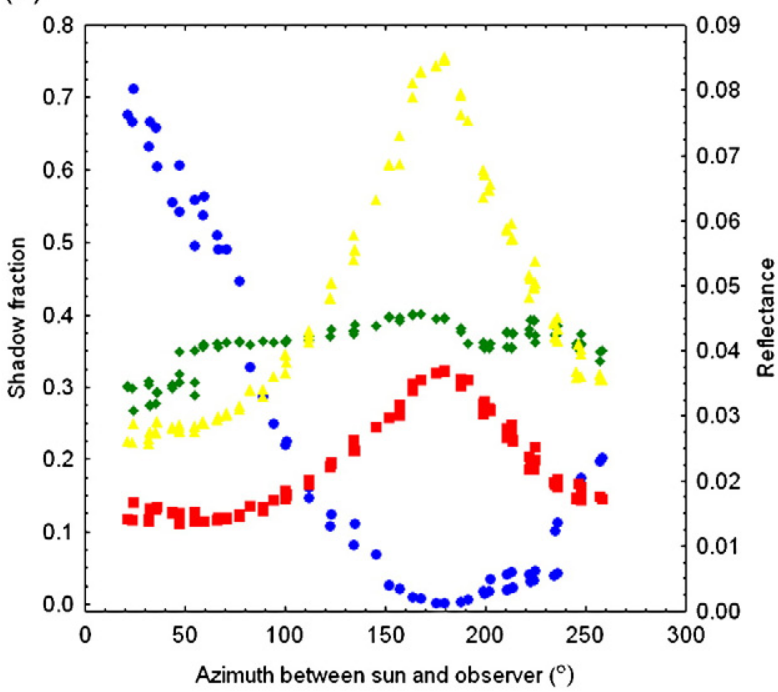

(b)

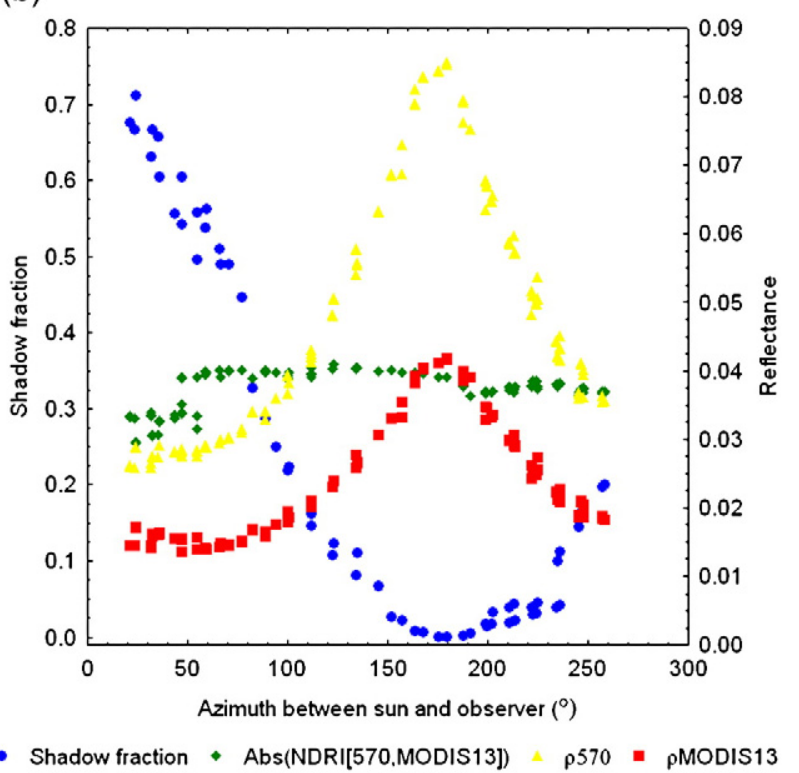

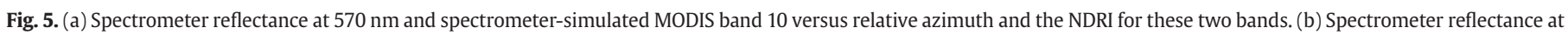
$570 \mathrm{~nm}$ and spectrometer-simulated MODIS band 13 versus NDRI for these two bands. 
(a)

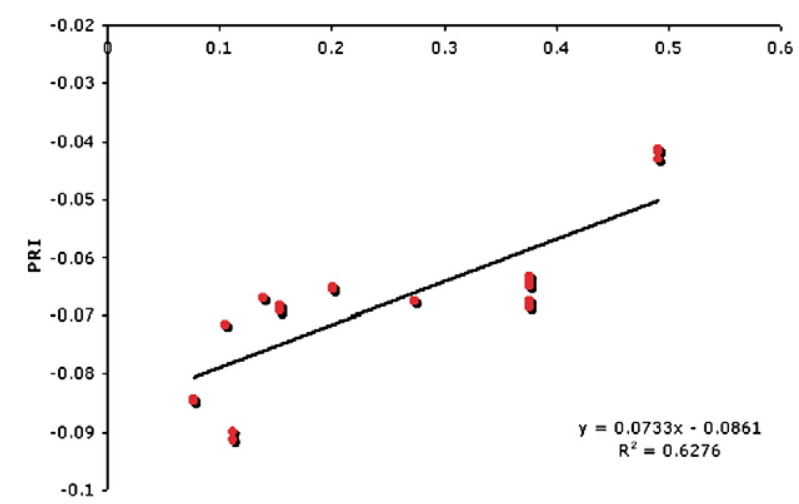

LUE ( $g C M J-1)$ (b)

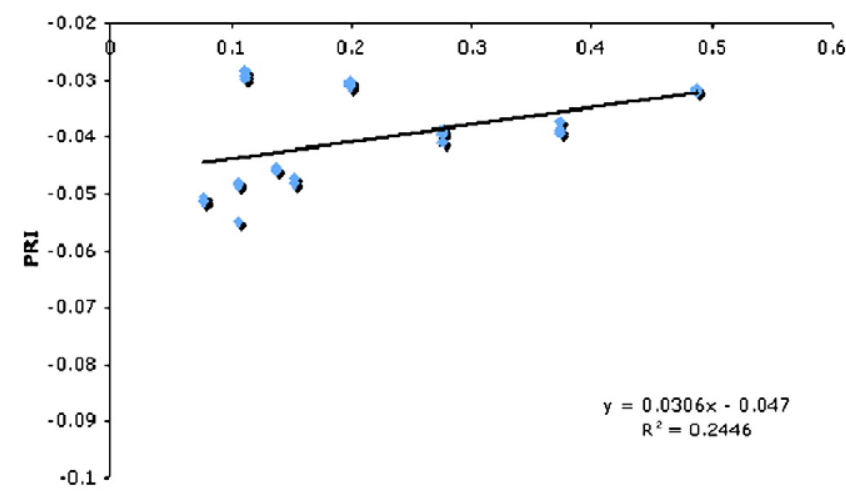

LUE (gCMJ-1)

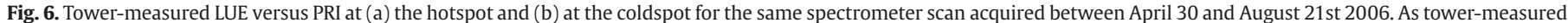

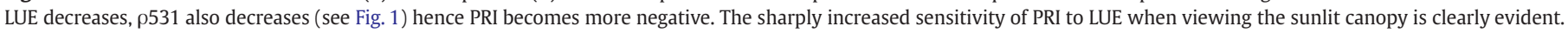

relationship for shaded leaves is significantly different than for sunlit leaves (slope less than half with a confidence $>95 \%$ ) compelling us to conclude that the variation of PRI is indeed caused by the xanthophyll cycle related response to light saturation-induced reductions in LUE. Changes in pigment pool sizes, which were previously shown to have a certain impact on PRI (Barton \& North, 2001) are unlikely to cause these variations in PRI, (1) as the location of sunlit and shaded leafs varies throughout the day as the radiometer observes a large number of different view and sun-angles, and (2) observed sub-hourly variations in PRI imply fast adaptations of leaf biochemistry to changing environmental conditions.

3.4. Are the bands used for PRI robust over time? Are other biological phenomena evident from other NDRIs?

The above theoretical and experimental analysis demonstrates that NDRI cannot vary with shadow fraction unless the reflectance of at least one of the bands used to compute the NDRI differ from shaded to sunlit portions of the canopy. An NDRI formed using the $531 \mathrm{~nm}$ band showed a clear dependence on shadow fraction (Fig. 4). We also demonstrated that when using two other spectral bands lying outside the $531 \mathrm{~nm}$ window for the detection band, that the NDRI formed from these bands did not vary with shadow fraction (Fig. 5).

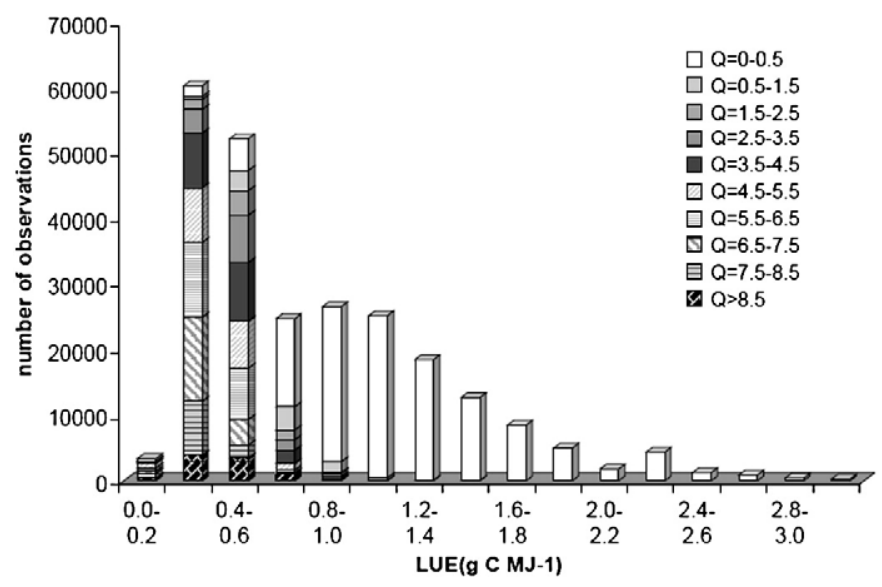

Fig. 7. Number of observations made for classes of homogeneous sky conditions and homogenous physiological states $(\varepsilon)$. A total of 31 classes were derived having 246,276 observations.
We now turn to the parametric approach of Hilker et al. (2008) described above to examine the dependence of the observed NDRIs on view and illumination geometry for all combinations of NDRIs between 400 and $900 \mathrm{~nm}$, under all sky conditions. Of the 160 possible combinations of direct to diffuse sky illumination conditions, $Q$ and LUE (10Q $\times 16$ LUE strata) only 31 had observations (Fig. 7). The LUE variations were largest under diffuse radiation conditions, ranging from 0 to $3.6 \mathrm{~g} \mathrm{C} \mathrm{MJ}^{-1}$.

Fig. $8 \mathrm{a}$ and $\mathrm{b}$ show the results of this analysis. Fig. 8a shows the coefficients of determination for the relationship between LUE and isotropic, geometric and volumetric kernels weights, respectively derived from a series of NDRIs using $570 \mathrm{~nm}$ as reference band and 154 different wavelengths between 400 and $900 \mathrm{~nm}$ as detection bands. The relationship culminates at around $536 \mathrm{~nm}$ with best correlations found for isotropic scattering component $\left(r^{2}=0.91, p<0.05\right),\left(r^{2}=0.71\right.$, $p<0.05$ ), for the geometric component and $r^{2}=0.72, p<0.05$ for the volumetric scattering component).

Fig. 8b shows the coefficients of determination for the relationship between $\varepsilon$ and isotropic, geometric and volumetric kernels weights derived from a series of NDRIs using $531 \mathrm{~nm}$ as detection band and 154 different wavelengths between 400 and $900 \mathrm{~nm}$ as reference bands. The relationship shows best results around $578 \mathrm{~nm}$ with correlations for the volumetric scattering component $\left(r^{2}=0.93\right.$, $p<0.05)$, for the isotropic component $\left(r^{2}=0.75, p<0.05\right)$, and for the geometric scattering component $\left(r^{2}=0.77, p<0.05\right)$. A high relationship is also found for the volumetric scattering component between an NDRI that includes the fluorescence band at $705 \mathrm{~nm}$.

Fig. 8a clearly demonstrates the strong xanthophyll signal seen in the $531 \mathrm{~nm}$ detection band at the whole canopy level, under a wide range of illumination and viewing conditions. A signal at around $705 \mathrm{~nm}$ from the volumetric scattering component is also apparent, possibly a result of chlorophyll fluorescence (Gitelson et al., 1999; Zarco-Tejada et al., 2002).

Our analysis also shows that the $570 \mathrm{~nm}$ band is the optimum reference band for PRI as seen in Fig. 8b where we chose $531 \mathrm{~nm}$ as the detection band for the NDRI, then examined the correlations between NDRI and LUE allowing the reference band to assume any value for the 154 different wavelengths.

Note that as predicted by $\mathrm{NH} 1$ and $\mathrm{NH} 2$, a strong correlation is also found when $531 \mathrm{~nm}$ is the detection band and $705 \mathrm{~nm}$ is the reference band for the volumetric scattering component, since both bands should show reflectance differences between sunlit and shaded leaves when the canopy is stressed. However, looking at Fig. 8b this relationship is highest for the NDRI using $570 \mathrm{~nm}$ as reference and 
(a)

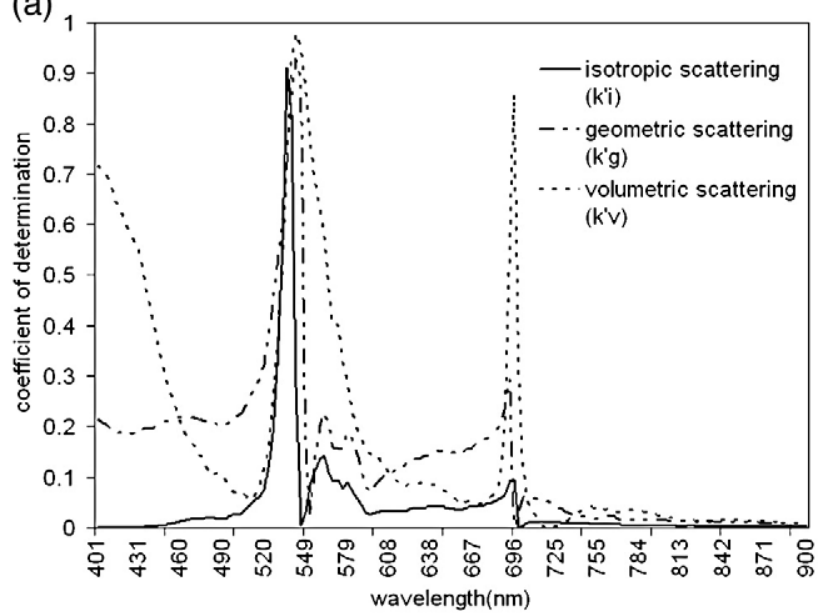

(b)

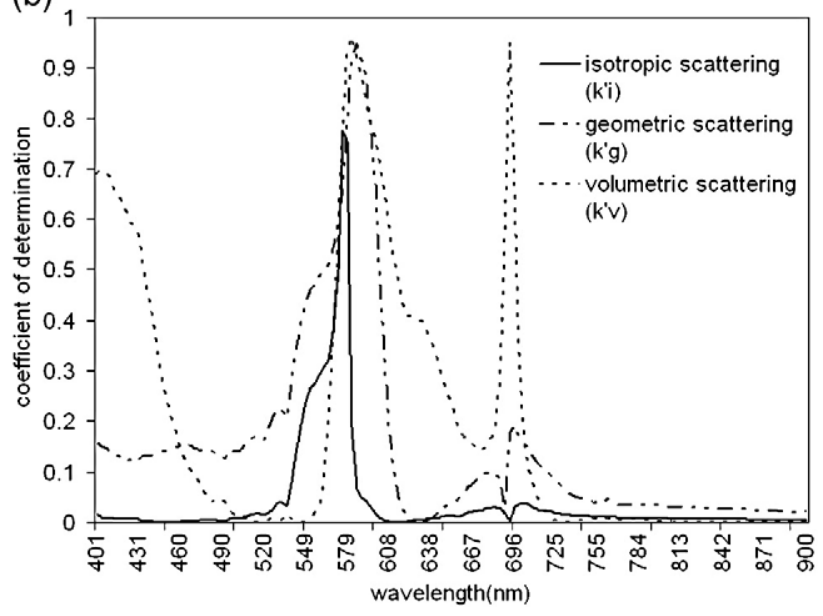

Fig. 8. a: Correlations as a function of the spectral location of the detection band with $570 \mathrm{~nm}$ as the reference band. Coefficients of determination for the relationship between LUE and NDRI (isotropic, geometric and volumetric kernels weights) derived from 154 different detection bands between 400 and $900 \mathrm{~nm}$. Correlation is maximum at $536 \mathrm{~nm}$ with best correlations found for isotropic scattering component $\left(r^{2}=0.91\right.$, $p<0.05),\left(r^{2}=0.71, p<0.05\right.$, for the geometric component and $r^{2}=0.72, p<0.05$ for the volumetric scattering component). b: Stability of the reference band. LUE vs NDRI correlations as a function of the spectral location of the reference band with $531 \mathrm{~nm}$ as the detection band. Coefficients of determination for the relationship between $\varepsilon$ and NDRIs (isotropic, geometric and volumetric kernels weights) derived from a series of using 154 different reference bands between 400 and $900 \mathrm{~nm}$. The relationship shows maximum correlation around $578 \mathrm{~nm}$ with best correlations found for the volumetric scattering component $\left(r^{2}=0.93, p<0.05\right),\left(r^{2}=0.75, p<0.05\right)$, for the isotropic component and $r^{2}=0.77, p<0.05$ for the geometric scattering component, respectively).

$705 \mathrm{~nm}$ as detection band. Once again, we interpret the $705 \mathrm{~nm}$ signal arising from chlorophyll fluorescence.

\section{Discussion}

Our observations and analysis lead us to conclude that observed PRI variations over a Douglas-fir forest, acquired for a range of sunlit and shaded canopy fractions, are directly related to physiological reductions in LUE in the canopy's light-saturated photosynthetic elements. We also found that simultaneous, additional reflectance changes were observed at around $705 \mathrm{~nm}$, possibly related to chlorophyll fluorescence associated with down-regulation.

These results suggest a novel space-borne sensor configuration for directly measuring xanthophyll-cycle induced changes in LUE. The sensor we propose is an imaging spectrometer that would measure the PRI at a range of shadow fractions for each landscape element and simultaneously measure shadow fraction in the sensor field of view, using for example mixture decomposition (Hall et al., 1995). The sensor would need to view the landscape at multiple along-track view angles (forward and aft of nadir). The landscape would also be imaged in multiple cross-track directions. Along each image track parallel to the orbital ground track, each landscape element would be viewed in a matter of a few milliseconds for a range of shadow fractions. The LUE so measured would combine both over and understory photosynthetically active forest stand elements. The sensor would contain $50 \mathrm{~nm}$ or narrower wide bands at $531 \mathrm{~nm}, 570 \mathrm{~nm}$, and $705 \mathrm{~nm}$ for measuring the degree of photosynthetic down-regulation as well as bands measuring the variation of canopy shadow fraction with observation angle, for example the bands used for Kauth-Thomas Brightness (Kauth \& Thomas, 1976). Additional bands for removal of atmospheric effects removal could be considered, or alternatively, atmospheric properties from other sensors used to retrieve surface reflectance in these bands. Depending on design considerations, and other mission information requirements, the spectrometer could be full-spectrum, or an instrument with the selected narrow bands mentioned above.

Our results demonstrate that the variation in the PRI signal with the fraction of canopy shadow viewed by the multi-angle spectrometer would result solely from canopy elements whose reflectance differs as a function of illumination intensity (i.e. between fully sunlit and shadow). Thus, the rate of change in the PRI signal with viewed shadow fraction would come only from the photosynthetically active elements of the canopy, hence for a given observation would be directly related to the level of light saturation within these elements. We also see from our analysis that the "curvature" of the PRI-shadow fraction (PRI-SF) relationship is related to the light saturation levels within the canopy. On overcast days the curvature is much less than on sunlit days where light saturation levels are much higher. Our results also suggest that such a relationship would be responsive only to the level of light saturation in the viewed plant canopies, and not to extraneous factors such as landscape variations in reflectance outside the detection bands.

\section{Conclusions}

(1) We have developed an inference framework, when used in combination with multi-view and illumination angle reflectance measurement sets, to conclude that PRI variations are due exclusively to changes in canopy reflectance at $531 \mathrm{~nm}$ and not variations in canopy geometry, chlorophyll concentrations, view or illumination differences.

(2) The inference framework is based in part on our finding that an NDRI does not vary with shadow fraction unless there is a difference in reflectance between the shaded and sunlit components of the canopy in at least one NDRI band. This important insight forms the basis for investigating the presence of biological mechanisms that manifest themselves in leaf reflectance changes.

(3) On the basis of canopy-scale full-spectrum spectrometer measurements we are able to show that only NDRIs formed from the 531 and $570 \mathrm{~nm}$ and $705 \mathrm{~nm}$ bands vary with shadow fraction and are correlated with measured values of LUE, hence demonstrate conclusively that the spectrometer-measured variation in PRI with tower-measured variation in LUE is due to canopy-scale variations in reflectance at $531 \mathrm{~nm}$. We conclude that these variations in reflectance are caused by light saturationinduced changes in the xanthophyll cycle pigments.

(4) A confirmation of the above conclusions comes from the difference we observe in the PRI-LUE slope between the hot spot and the dark spot. The slope of the LUE-PRI relationship for the dark spot is less than half that for the hot spot.

(5) We confirmed that the spectral regions around $531 \mathrm{~nm}$ and $570 \mathrm{~nm}$ are the most suitable PRI detection and reference 
bands. The significant relationship between the volumetric scattering component for the BRDF surface derived from an NDRI using $570 \mathrm{~nm}$ and $705 \mathrm{~nm}$ as reference and detection band, respectively shows the potential of this combination of bands to sense $\varepsilon$ from chlorophyll fluorescence.

(6) Our findings suggest a flux tower-based capability, as well as a new space-borne sensor and methodology for the direct retrieval from space of changes in light use efficiency, hence gross ecosystem production, by measuring the PRI at a function of shadow fraction using a multi-angle spectrometer that can simultaneously retrieve shadow fraction and PRI. Such observations, when used in combination with physiological models should provide a greatly improved capability to monitor surface atmosphere exchanges of moisture, carbon and heat.

\section{Acknowledgements}

We would like to acknowledge support from Dr. Diane Wickland's Terrestrial Ecology and Dr. Andy Black's colleagues for access to their tower, their data and other equipment at the Fluxnet Canada Douglasfir site. Without the Fluxnet Canada organization, careful calibration procedures and other elements of an excellent experimental design, this investigation would not have been possible. We would also like to acknowledge the contributions of the comments from this paper's anonymous referees, which have added enormously to the lucidity of the paper and accuracy of its literature citations.

\section{References}

Adams, W. W., \& Demmig-Adams, B. (1994). Carotenoid composition and down regulation of photosystem II in three conifer species during the winter. Physiologia Plantarum, 92, 451-458.

Asner, G. P. (1998). Biophysical and biochemical sources of variability in canopy reflectance. Remote Sensing of Environment, 64, 234-253.

Asner, G. P., Nepstad, D., Cardinot, G., \& Ray, D. (2004). Drought stress and carbon uptake in an Amazon forest measured with spaceborne imaging spectrometry. PNAS, 101, 6039-6044.

Ball, J. T., Woodrow, I. E., \& Berry, J. A. (1986). A model predicting stomatal conductance and its contribution to the control of photo synthesis under different environmental conditions. In J. Biggins (Ed.), Progress in photosynthesis research (pp. 221-225). Dodrecht, the Netherlands: Nijhoff.

Barton, C. V. M., \& North, P. R. J. (2001). Remote sensing of canopy light use efficiency using the photochemical reflectance index-Model and sensitivity analysis. Remote Sensing of Environment, 78(3), 264-273.

Black, T. A., Den Hartog, G., Neumann, H. H., Blanken, P. D., Yang, P. C., Russell, C., et al. (1996). Annual cycles of water vapour and carbon dioxide fluxes in and above a boreal aspen forest. Global Change Biology, 2, 219-229.

Chen, J. M., \& Black, T. A. (1991). Measuring leaf-area index of plant canopies with branch architecture. Agricultural and Forest Meteorology, 57, 1-12.

Chen, J. M., \& Leblanc, S. G. (1997). A four-acale bidirectional reflectance model based on canopy architecture. IEEE Transactions on Geoscience and Remote Sensing, 35, 1316-1337.

Collelo, G. D., Grivet, C., Sellers, P. J., \& Berry, J. A. (1998). Modeling of energy, water, and CO2 flux in a temperate grassland ecosystem with SiB2: May-October 1987. Journal of Atmospheric Sciences, 55, 1141-1146.

Demmig-Adams, B., \& Adams, W. W. (1992). Photoprotection and other responses of plants to light stress. Annual Reviews of Plant Physiology and Molecular Biology, 43, 599-626.

Demmig-Adams, B., Gilmore, A. M., \& Adams, W. W., III (1996). In vivo functions of carotenoids in higher plants. FASEB J, 10, 403-412.

Dickenson, R., Shaikh, M., Bryant, R., \& Graumlich, L. (1998). Interactive canopies for a climate model. Journal of Climate, 11, 2823-2836.

Drolet, G. G., Huemmrich, K. F., Hall, F. G., Middleton, E. M., Black, T. A., Barr, A. G., \& Margolis, H. A. (2005). A MODIS-derived photochemical reflectance index to detect inter-annual variations in the photosynthetic light-use efficiency of a boreal deciduous forest. Remote Sensing of Environment, 98, 212-224.

Drolet, G. G., Middleton, E. M., Huemmrich, K. F., Hall, F. G., Amiro, B. D., Barr, A. G., et al., (in press), Regional mapping of gross light-use efficiency using MODIS spectral indices. Remote Sensing of Environment.

Filela, I., Amaro, J. L., \& Penuelas, J. (1996). Relationship between photosynthetic radiation-use efficiency of barley canopies and the photochemical reflectance index (PRI). Physiologia Plantarum, 96, 211-216.

Fuentes, D., Gamon, J. A., Cheng, Y., Qiu, H.-L., Mao, Z., Sims, D. A., et al. (2006). Mapping carbon and water flux in a chaparral ecosystem using vegetation indices derived from AVIRIS. Remote Sensing of Environment, 103, 312-323.

Gamon, J. A., Field, C. B., Bjorkman, O., Artree, A., \& Peñuelas, J. (1990). Remote sensing of the xantophyll cycle and chlorophyll fluorescence in sunflower leaves and canopies. Oecologia, 85, 1-7.
Gamon, J. A., Penuelas, J., \& Field, C. B. (1992). A narrow-waveband spectral index that tracks diurnal changes in photosynthetic efficiency. Remote Sensing of Environment, $41,35-44$.

Gamon, J. A., Filella, I., \& Peñuelas, J. (1993). The dynamic 531-nanometer reflectance signal: a survey of twenty angiosperm species. In H. Y. Yamamoto \& C. M. Smith (Eds.), Photosynthetic Responses to the Environment (pp. 172-177). Rockville: American Society of Plant Physiologists.

Gamon, J. A., Serrano, L., \& Surfus, J. S. (1997). The photochemical reflectance index: an optical indicator of photosynthetic radiation use efficiency across species, functional types, and nutrient levels. Oecologia, 112, 492-501.

Gamon, J. A., \& Surfus, J. S. (1999). Assessing leaf pigment content and activity with a reflectometer. New Phytologist, 143, 105-117.

Gamon, J. A., Field, C. B., Fredeen, A. L., \& Thayer, S. (2001). Assessing photosynthetic downregulation in sunflower stands with an optically-based mode. Photosynthesis Research, 67, 113-125.

Gerstl, S. A. W., \& Borel, C. C. (1992). Principles of the radiosity method versus radiativetransfer for canopy reflectance modeling. IEEE Transactions on Geoscience and Remote Sensing, 30, 271-275.

Gitelson, A. A., Buschmann, C., \& Lichtenthaler, H. K. (1999). The Chlorophyll Fluorescence Ratio F-735/F-705 as an accurate measure of the chlorophyll content in plants. Remote Sensing of Environment, 69, 296-302.

Goodwin, G. (1937). Regeneration Study on the logged-off lands of the Comox Logging and Railway Company Oyster River Forest Survey No R 72 Survey file No 0124780 BC Forest Service 39p and Map.

Goulden, M. L., \& Crill, P. M. (1997). Automated measurements of $\mathrm{CO}_{2}$ exchange at the moss surface of a black spruce forest. Tree Physiology, 17, 537-542.

Guo, J. M., \& Trotter, C. M. (2004). Estimating photosynthetic light-use efficiency using the photochemical reflectance index: Variations among species. Functional Plant Biology, 31, 255-265.

Hall, F. G., Masek, J. G., \& Collatz, J. G. (2006). Evaluation of ISLSCP Initiative II FASIR and GIMMS NDVI products: Implications for climate data records from satellite observations. JGR Atmospheres, 111, D22S08. doi:10.1029/2006JD007438.

Hall, F. G., Shimabukuro, Y. E., \& Huemmrich, K. F. (1995). Remote sensing of forest biophysical structure in boreal stands of Picea Mariana using mixture decomposition and geometric reflectance models. Ecological Applications, 5(4), 993-1013.

Hilker, T., Coops, N. C., Nesic, Z., Wulder, M. A., \& Black, A. T. (2007). Instrumentation and approach for unattended year round tower based measurements of spectral reflectance. Computers and Electronics in Agriculture, 56, 72-84.

Hilker, T., Coops, N. C., Schwalm, C. R., Jassal, R. S., Black, T. A., \& Krishnan, P. (2008). Effects of mutual shading of tree crowns on prediction of photosynthetic light-use efficiency in a coastal Douglas-fir forest. Tree Physiology, 28, 825-834.

Hilker, T., Coops, N. C., Hall, F. G., Black, T. A., Wulder, M. A. Nesic, Z., \& Krishnan, P. (in press). Separating physiologically and directionally induced changes in PRI using BRDF models. Remote Sensing of Environment. doi:10.1016/j.rse.2008.01.011.

Humphreys, E. R., Black, T. A., Morgenstern, K., Cai, T. B., Drewitt, G. B., Nesic, Z., et al. (2006). Carbon dioxide fluxes in coastal Douglas-fir stands at different stages of development after clearcut harvesting. Agricultural and Forest Meteorology, 140, 6-22.

Justice, C. O., Vermote, E., Townshend, J. R. G., Defries, R., Roy, D. P., Hall, D. K., et al (1998). The Moderate Resolution Imaging Spectroradiometer (Modis): Land remote sensing for global change research. IEEE Transactions on Geoscience and Remote Sensing, 36, 1228-1249.

Kauth, R. J., \& Thomas, G. S. (1976). The tasseled cap-A graphic description of the spectraltemporal development of agricultural crops as seen by Landsat. Proceedings, Symposium on Machine Processing of Remotely Sensed Data (pp. 41-51). West Lafayette, IN: LARS.

Los, S. O., North, P. R. J., Grey, W. M. F., \& Barnsley, M. J. (2005). A method to convert AVHRR normalized difference vegetation index time series to a standard viewing and illumination geometry. Remote Sensing of Environment, 99, 400-411.

Lucht, W., Hyman, A. H., Strahler, A. H., Barnsley, M. J., Hobson, P., \& Muller, J. P. (2000). A comparison of satellite-derived spectral albedos to ground-based broadband albedo measurements modeled to satellite spatial scale for a semi-desert landscape. Remote Sensing of Environment, 74, 85-98.

Monteith, J. L. (1972). Solar-radiation and productivity in tropical ecosystems. Journal of Applied Ecology, 9, 747-766.

Monteith, J. L. (1977). Climate and efficiency of crop production in Britain. Philosophical Transactions of the Royal Society of London, Series B, 281, 271-294.

Morgenstern, K., Black, T. A., Humphreys, E. R., Griffis, T. J., Drewitt, G. B., Cai, T. B., et al. (2004). Sensitivity and uncertainty of the carbon balance of a pacific northwest Douglas-fir forest during an el nino la nina cycle. Agricultural and Forest Meteorology, 123, 201-219.

Nichol, C. J., Huemmrich, K. F., Black, T. A., Jarvis, P. G., Walthall, C. L., Grace, J., et al. (2000). Remote sensing of photosynthetic light use efficiency of boreal forest. Agriculture Forest Meteorology, 101, 131-142.

Nichol, C. J., Lloyd, J., Shibistova, O., Arneth, A., Roser, C., Knohl, A., et al. (2002). Remote sensing of photosynthetic-light-use efficiency of a Siberian boreal forest. Tellus Series B-Chemical and Physical Meteorology, 54, 677-687.

Niyogi, K. K. (1999). Photoprotection revisited: Genetic and molecular approaches. Annual Reviews of Plant Physiology and Plant Molecular Biology, 50, 333-359.

Osmond, C. B., Anderson, J. M., Ball, M. C., \& Egerton, J. J. G. (1999). Compromising efficiency: the molecular ecology of light resource utilization in plants. In M. C Press J. D. Scholes \& M. G. Barker (Eds.), Physiological plant ecology (pp. 1-25) Oxford: Blackwell Science Ltd.

Pellegrini, L., Boni, P., \& Carton, A. (2003). Hydrographic evolution in relation to neotectonics aided by data processing and assessment: some examples from the Northern Apennines (Italy). Quaternary International, 101, 211-217. 
Penuelas, J., Biel, C., \& Estiarte, M. (1993). Changes in biomass, chlorophyll content and gas-exchange of beans and peppers under nitrogen and water-stress. Photosynthetica, 29, 535-542.

Peñuelas, J., Filella, I., \& Gamon, J. A. (1995). Assessment of photosynthetic radiation-use efficiency with spectral reflectance. New Phytologist, 131(3), 291-296.

Peñuelas, J., Gamon, J. A., Fredeen, A. L., Merino, J., \& Field, C. B. (1994). Reflectance indexes associated with physiological changes in nitrogen-limited and water-limited sunflower leaves. Remote Sensing of Environment, 48(2), 135-146.

Peñuelas, J., Llusia, J., Pinol, J., \& Filella, I. (1997). Photochemical reflectance index and leaf photosynthetic radiation-use-efficiency assessment in Mediterranean trees. International Journal of Remote Sensing, 18(13), 2863-2868.

Pfundel, E., \& Bilger, W. (1994). Regulation and possible function of the violaxanthin cycle. Photosynthesis Research, 42, 89-109.

Rahman, A. F., Cordova, V. D., Gamon, J. A., Schmid, H. P., \& Sims, D. A. (2004). Potential of ODIS ocean bands for estimating CO2 flux from terrestrial vegetation: A novel approach. Geophysical Research Letters, 31, L10503. doi:10.1029/2004GL019778.

Rahman, A. F., Gamon, J. A., Fuentes, D. A., Roberts, D., \& Prentiss, D. (2001). Modeling spatially distributed ecosystem flux of boreal forest using hyperspectral indices from AVIRIS imagery. Journal of Geophysical Research, 106(D24), 33,579-33,591.

Roujean, J. L., Leroy, M., \& Deschamps, P. Y. (1992). A bidirectional reflectance model of the Earth's surface for the correction of remote-sensing data. Journal of Geophysical Research-Atmospheres, 97, 20455-20468.

Running, S. W., Nemani, R. R., Heinsch, F. A., Zhao, M. S., Reeves, M., \& Hashimoto, H (2004). A continuous satellite-derived measure of global terrestrial primary production. Bioscience, 54, 547-560.

Schwalm, C. R., Black, T. A., Arniro, B. D., Arain, M. A., Barr, A. G., Bourque, C. P. A., et al. (2006). Photosynthetic light use efficiency of three biomes across an East-West continental-scale transect in Canada. Agricultural and Forest Meteorology, 140, 269-286.

Sellers, P. J. (1985). Canopy reflectance, photosynthesis and transpiration. International Journal of Remote Sensing, 6, 1335-1372.
Sellers, P. J. (1987). Canopy reflectance, photosynthesis, and transpiration 2 . The role of biophysics in the linearity of their interdependence. Remote Sensing of Environment, $21,143-183$.

Sellers, P. J., Berry, J. A., Collatz, G. J., Field, C. B., \& Hall, F. G. (1992). Canopy reflectance, photosynthesis and transpiration. Part III: A reanalysis using enzyme kinetics-electron transport models of leaf physiology. Remote Sensing of Environment, 42, 187-216.

Sellers, P. J., Hall, F. G., Asrar, G., Strebel, D. E., \& Murphy, R. E. (1992). An overview of the First International Satellite Land Surface Climatology Project (ISLSCP) Field Experiment (FIFE). Journal of Geophysical Research, 97, 18,345-18,371.

Sims, D. A., \& Gamon, J. A. (2002). Relationships between leaf pigment content and spectral reflectance across a wide range of species, leaf structures and developmental stages. Remote Sensing of Environment, 81, 337-354.

Strahler, A. H., \& Jupp, D. L. B. (1990). Modeling bidirectional reflectance of forests and woodlands using boolean models and geometric optics. Remote Sensing of Environment, 34, 153-166.

Strugnell, N. C., \& Lucht, W. (2001). An algorithm to infer continental-scale albedo from AVHRR data, land cover class, and field observations of typical BRDFs. Journal of Climate, 14, 1360-1376.

Turner, D. P., Ritts, W. D., Cohen, W. B., Maeirsperger, T. K., Gower, S. T., Kirschbaum, A. A., et al. (2005). Site-level evaluation of satellite-based global terrestrial gross primary production and net primary production monitoring. Global Change Biology, 11, 666-684.

Van Den Eeckhaut, M., Poesen, J., Verstraeten, G., Vanacker, V., Moeyersons, J., Nyssen, J., et al. (2005). The effectiveness of Hillshade maps and expert knowledge in mapping old deep-seated landslides. Geomorphology, 67, 351-363.

Wanner, W., Li, X., \& Strahler, A. H. (1995). On the derivation of kernels for kernel-driven models of bidirectional reflectance. Journal of Geophysical Research-Atmospheres, 100, 21077-21089.

Zarco-Tejada, P. J., Miller, J. R., Mohammed, G. H., Noland, T. L., \& Sampson, P. H. (2002). Vegetation stress detection through chlorophyll $\mathrm{a}+\mathrm{b}$ estimation and fluorescence effects on hyperspectral imagery. Journal of Environmental Quality, 31, 1433-1441. 